\title{
Analisis Densitas, Porositas, dan Struktur Mikro Batu Apung Lombok dengan Variasi Lokasi menggunakan Metode Archimedes dan Software Image-J
}

\author{
Mohammad Ridha* dan Darminto ${ }^{\dagger}$ \\ Jurusan Fisika, Fakultas Matematika dan Ilmu Pengetahuan Alam, \\ Institut Teknologi Sepuluh Nopember (ITS), Kampus ITS Sukolilo, Surabaya 60111
}

\begin{abstract}
Intisari
Paper ini menjelaskan karakterisasi dan analisis densitas, porositas, dan struktur mikro batu apung Lombok sebagai bahan komposit alam. Batu apung diambil dari tiga lokasi di Lombok yaitu desa Ijobalit (lokasi I), desa Lendang Nangka (lokasi II), dan desa Karang Sidemen (lokasi III) dengan kedalaman galian $\pm 0,3$ meter dan \pm 3,0 meter dari permukaan tanah. Batu apung dicuci, dikeringkan, dan dibentuk sampel uji. Sifat densitas dan porositas diuji dengan metode Archimedes. Struktur mikro dikarakterisasi dengan SEM dan hasilnya dianalisis dengan software Image-J untuk mendapatkan nilai porositas dan ukuran luas penampang pori rata-rata. Penelitian ini mendapatkan nilai densitas sebesar $(0,610-0,753) \mathrm{gram} / \mathrm{cm}^{3}$, densitas kering sebesar $(0,594-0,737)$ $\mathrm{gram} / \mathrm{cm}^{3}$, densitas jenuh sebesar $(1,057-1,148) \mathrm{gram} / \mathrm{cm}^{3}$, dan porositas sebesar $(32,03-51,20) \%$. Nilai densitas tertinggi diperoleh dari sampel lokasi II kedalaman galian $\pm 0,3$ meter dari permukaan tanah. Nilai porositas tertinggi diperoleh dari sampel lokasi III kedalaman galian $\pm 0,3$ meter. Lokasi deposit batu apung mempengaruhi densitas dan porositasnya. Hasil mikrografi SEM menunjukkan bahwa batu apung Lombok tersusun atas pori-pori yang terdistribusi merata dengan ukuran berbeda-beda. Analisis menggunakan software Image-J mendapatkan porositas sebesar $(38,38-56,80) \%$. Berdasarkan hasil ini software Image-J relevan digunakan untuk menentukan porositas dari mikrografi SEM sampel batu apung Lombok.
\end{abstract}

\begin{abstract}
This paper explains the characterization and analysis of density, porosity, and microstructure of Lombok pumice as natural composite materials. Pumice is taken from three locations in Lombok, there are desa Ijobalit (location I), desa Lendang Nangka (location II), and desa Karang Sidemen (location III) with a depth of excavation $\pm 0,3$ meters and $\pm 3,0$ meters of ground level. Pumice is washed, dried, and formed to be samples test. Density and porosity of sample are tested by Archimedes method. Microstructure of sample is characterized by SEM and the results are analyzed by Image-J software to get porosity and the average pore size of cross-sectional area. This research get natural density is $(0,610-0,753)$ gram $/ \mathrm{cm}^{3}$, dry density is $(0,594-0,737) \mathrm{gram} / \mathrm{cm}^{3}$, saturated density is $(1,057-1,148) \mathrm{gram} / \mathrm{cm}^{3}$, and porosity value is $(32,03-51,20) \%$. The highest natural density value is obtained from the sample of location III with a depth of excavation $\pm 0,3$ meters of ground level. The highest porosity value is obtained from the sample of location III with a depth of excavation $\pm 0,3$ meters of ground level. The results of SEM micrographs of sample show that Lombok pumice is composed by pores which are uniformly distributed with different sizes. By using Image-J software, analysis of the SEM micrographs of sample get the porosity value is $(38,38-56,80) \%$. So, Image-J software is relevant used to determine porosity of the SEM micrograph of Lombok pumice sample.
\end{abstract}

KATA KUNCI: pumice stone, natural composite, Vickers method, Image-J software

\section{PENDAHULUAN}

Letak Indonesia yang berada di atas lempeng vulkanik Eurasia-Australia-Pasifik (Ring of fire) menjadikan Indonesia memiliki deposit bahan galian mineral non-logam yang melimpah. Aktifitas-aktifitas vulkanik yang terjadi sejak dulu membentuk endapan geologi berumur tersier hingga kuarter berupa batuan beku, sedimen, metamorf dan piroklastik

\footnotetext{
*E-MAIL: ridha.moh.13@mhs.physics.its.ac.id

†E-MAIL: darminto@physics.its.ac.id
}

hingga saat ini.

Batuan beku terbentuk dari cairan magma yang membeku akibat mengalami proses pendinginan [1]. Batuan sedimen (endapan) terbentuk sebagai akibat pengendapan material yang berasal dari pecahan, bongkahan batu yang hancur karena proses alam, kemudian terangkut oleh air, angin, es, dan terakumulasi dalam suatu tempat (cekungan), kemudian termampatkan menjadi suatu lapisan batuan baru [2]. Batuan metamorf berasal dari batuan beku dan batuan sedimen yang termalihkan (mengalami perubahan) di dalam bumi sebagai akibat tekanan dan temperatur sangat tinggi yang mengakibatkan perubahan sifat fisika dan kimia dari batuan asal. Batuan piroklastik berasal dari endapan produk erupsi gunung api 
seperti obsidian, scoria, andesitik, basaltik, dan pumice (batu apung).

Batu apung merupakan jenis material alam yang berasal dari endapan material piroklastik hasil aktivitas vulkanik gunung api [3]. Endapan piroklastik adalah endapan vulkaniklastik primer yang tersusun oleh partikel (piroklas) terbentuk oleh erupsi yang eksplosif dan terendapkan oleh proses vulkanik primer (jatuhan, aliran, surge) [4]. MBatu apung berupa mineral alam yang berasal dari gunung berapi terbentuk akibat pendinginan secara cepat gas-gas dan materialmaterial vulkanik [5]. Struktur batu apung tersusun atas rongga-rongga yang terbentuk akibat gelembung udara yang terperangkap dalam lava saat terjadi pembekuan [6]. Sebagai batuan yang terbentuk secara alami, batu apung secara umum tersusun dari senyawa-senyawa kimia berupa mineral oksida seperti $\mathrm{SiO}_{2}, \mathrm{Al}_{2} \mathrm{O}_{3}, \mathrm{Fe}_{2} \mathrm{O}_{3}, \mathrm{~K}_{2} \mathrm{O}, \mathrm{CaO}, \mathrm{Na}_{2} \mathrm{O}, \mathrm{TiO}_{2}$, serta $\mathrm{MgO}$ yang menyatu membentuk komposit alam.

Komposit didefinisikan sebagai suatu material yang terbentuk dari dua atau lebih material pem-bentuk yang memiliki sifat fisika dan kimia ber-beda, bercampur membentuk material baru yang memiliki sifat yang lebih unggul dari materialmaterial pembentuknya. Sebagai suatu bahan komposit alam, batu apung memiliki sifat fisis, sifat kimiawi, dan sifat mekanis. Dalam penelitian ini, fokus perhatian kajian adalah sifat fisis batu apung Lombok, yakni densitas dan porositasnya.

Densitas merupakan sifat fisis yang menggam-barkan kerapatan ikatan material-material penyu-sun batuan. Tingkat densitas batuan dipengaruhi oleh jenis dan jumlah mineral serta persentasenya, porositas batuan, dan fluida pengisi rongga. Densitas batuan meliputi densitas asli (natural density) yaitu densitas batuan dalam keadaan aslinya, densitas kering (dry density) yaitu densitas batuan dalam keadaan susut setelah batuan dipanaskan, dan densitas jenuh (saturated density) yaitu densitas batuan dalam keadaan jenuh setelah batuan dijenuhkan dalam suatu fluida.

Porositas didefinisikan sebagai perbandingan antara volume ruang yang terdapat diantara serbuk yang berupa poripori (ruang diantara serbuk yang selalu terisi oleh fluida seperti udara, minyak atau gas bumi) terhadap volume serbuk secara keseluruhan [7].

Porositas batuan merupakan rasio volume rongga-rongga pori terhadap volume total seluruh batuan yang dinyatakan dalam persen. Porositas bergantung pada jenis bahan, ukuran bahan, distribusi pori, sementasi, riwayat diagenetik dan komposisinya [8]. Suatu batuan dikatakan memiliki porositas efektif apabila bagian rongga-rongga dalam batuan saling berhubungan dan biasanya lebih kecil dari rongga-rongga pori. Ada dua jenis porositas yang dikenal dalam teknik reservoir, yaitu porositas absolut merupakan rasio volume pori-pori total batuan terhadap volume total batuan dan porositas efektif merupakan rasio volume pori-pori yang saling berhubungan terhadap volume total batuan.

Densitas dan porositas material dipengaruhi oleh struktur mikronya. Struktur mikro member-kan informasi tentang orientasi kristalin, distribusi material penyusun, cacat, batas butir, ukuran butir atau pori. Batu apung tersusun atas poripori yang terdistribusi merata dengan ukuran yang berbedabeda. Porositas dan ukuran pori dapat dianalisis dari tampi-

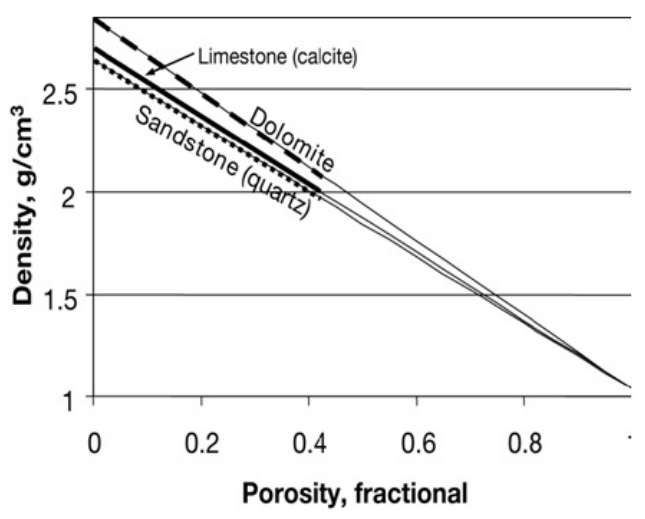

Gambar 1: Grafik relasi densitas dengan porositas pada limestone, dolomite, dan sandstone [9].

lan mikrografi SEM sampel dengan menggunakan software Image-J.

Image-J merupakan perangkat lunak yang dapat diunduh secara gratis dari http://rsb.info.nih.gov/ij/. Perangkat lunak yang telah diunduh dapat dipasangkan ke computer dengan menjalankan paket program tersebut. Ada dua macam versi yang dapat diunduh melalui alamat tersebut yaitu versi-32 bit dan versi-64 bit. Image-J dapat diupgrade versi terbarunya dengan cara membuka Image-J lalu mengklik Help > Update atau dengan cara membuka link http://rsb.info.nih.gov/ij/upgrade/ [10].

\section{METODOLOGI}

\section{Peralatan dan bahan}

Peralatan yang digunakan untuk membuat ukuran sampel adalah pemotong besi, penggaris, cutter, dan amplas. Peralatan yang digunakan ketika pengujian adalah gelas plastik, gelas beker, neraca digital, pemanas Furnace Tube, dan seperangkat alat uji SEM. Bahan yang digunakan adalah batu apung dari pulau Lombok.

\section{Pengambilan sampel}

Sampel batu apung diambil dari tiga lokasi di pulau Lombok, yaitu desa:

1. Ijobalit Lombok Timur, ketinggian 0-30 meter dpl

2. Lendang Nangka Lombok Timur, ketinggian 300-500 meter dpl

3. Karang Sidemen Lombok Tengah, ketinggian 500-1000 meter dpl

Kedalaman galian pengambilan sampel adalah $\pm 0,3$ meter dan $\pm 3,0$ meter dari permukaan. 


\section{Pembuatan sampel uji}

Batu apung dibersihkan (dicuci), dikeringkan, dan dipotong dengan ukuran $\pm(0,5 \times 1,5 \times 2) \mathrm{cm}^{3}$ untuk uji densitas dan porositas dengan metode Archimedes. Ukuran $\pm(1 \times 1 \times 1)$ $\mathrm{cm}^{3}$ untuk karakterisasi struktur mikro dengan SEM.

\section{Uji densitas dan porositas}

Pada metode Archimedes, besaran yang diukur adalah massa percontoh asli $\left(\mathrm{m}_{n}\right)$, massa percontoh kering $\left(\mathrm{m}_{o}\right)$, massa percontoh jenuh $\left(\mathrm{m}_{w}\right)$, massa (bejana + air + sampel tenggelam) $\left(\mathrm{m}_{a}\right)$ dan massa (bejana + air + sampel tergantung di air $)\left(m_{b}\right)$

\section{Perhitungan Data}

Berat percontoh jenuh dalam air

$$
\mathrm{m}_{s}=\mathrm{m}_{a}-\mathrm{m}_{b}(\text { gram })
$$

Volume percontoh tanpa pori

$$
V_{p}=\frac{m_{\circ}-m_{s}}{\rho_{a r}} \mathrm{~cm}^{3}
$$

Volume percontoh total

$$
V_{b}=\frac{m_{w}-m_{s}}{\rho_{a r}} \mathrm{~cm}^{3}
$$

Berat isi asli (natural density)

$$
\gamma=\frac{m_{n}}{V_{b}} \mathrm{gr} / \mathrm{cm}^{3}
$$

Berat isi kering (dry density)

$$
\gamma=\frac{m_{\circ}}{V_{b}} \mathrm{gr} / \mathrm{cm}^{3}
$$

Berat isi jenuh (saturated density)

$$
\gamma=\frac{m_{w}}{V_{b}} \mathrm{gr} / \mathrm{cm}^{3}
$$

Kadar air jenuh

$$
w=\frac{m_{w}-m_{\circ}}{m_{\circ}} \times 100 \%
$$

Porositas

$$
\varphi=\frac{m_{w}-m_{\circ}}{m_{w}-m_{s}} \times 100 \%
$$

Tahapan uji densitas dan porositas dengan metode Archimedes seperti Gambar 2.

\section{Uji Struktur Mikro dan Analisis dengan Software Image-J}

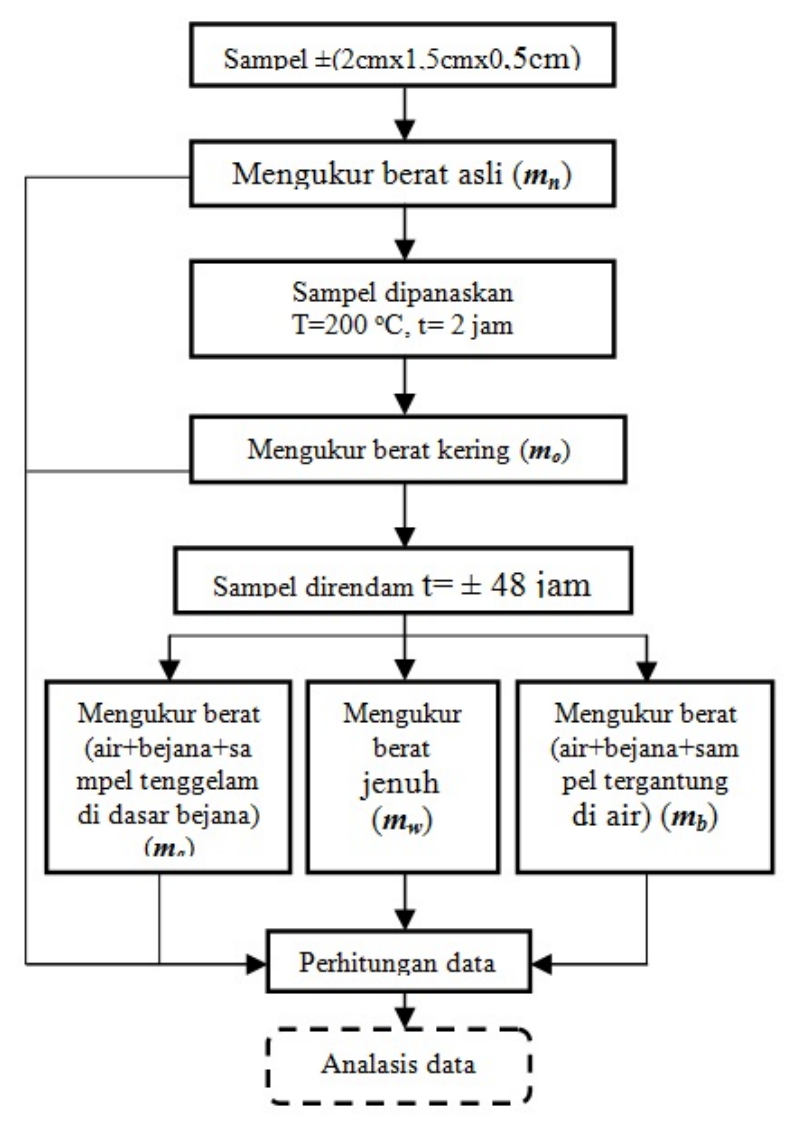

Gambar 2: Flowchart uji densitas dan porositas dengan metode Archimedes.

Struktur mikro batu apung dikarakterisasi dengan menggunakan SEM. Hasil mikrografi batu apung selanjutnya dianalisis dengan menggunakan software Image-J untuk mengetahui ukuran pori permukaan batu apung tersebut. Analisis mikrografi SEM sampel meliputi tiga tahapan sebagai berikut:

1. Tahap persiapan gambar

Langkah pada tahap ini meliputi start open software Image-J $>$ open file mikrografi SEM sampel $>$ pilih menu Analyze $>$ Set Scale $(\mathrm{nm}, \mu \mathrm{m})>$ pilih menu Image $>$ Crop gambar. Hasil gambar pada tahap ini ditunjukkan Gambar 3.

2. Tahap threshold gambar

Tahap ini merupakan tahap segmentasi warna gambar. Pada tahap ini, warna dibedakan menjadi warna partikel atau pori dan warna latar belakang (baground) [10]. Langkah pada tahap ini adalah pilih menu Image $>A d$ just $>$ Threshold $>$ Setting ukuran warna berdasarkan topografi gambar. Hasil gambar pada tahap ini ditunjukkan Gambar 4.

3. Tahap analisis gambar

Langkah dalam tahap ini adalah pilih menul Analyze $>$ Set parameter $>O k$ i pilih kembali menu Analyze $>$ Analyze Particles. Nilai data hasil analisis keluar dalam 


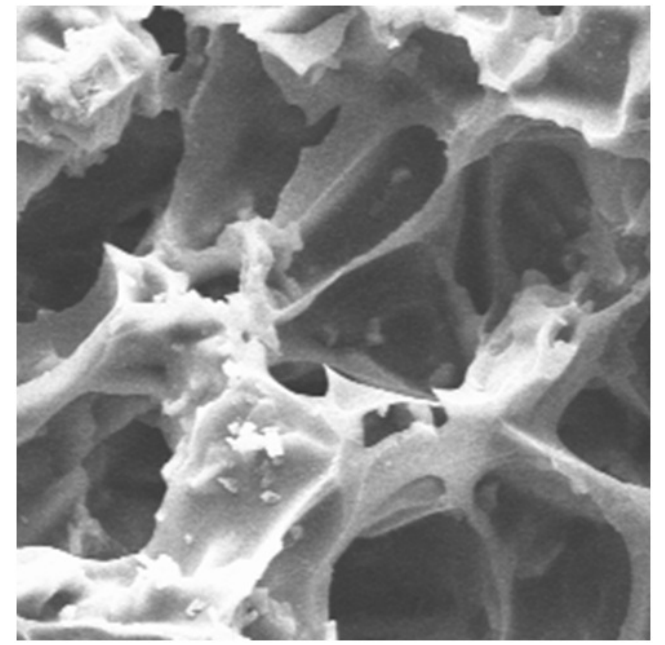

Gambar 3: Tampilan mikrografi SEM sampel.

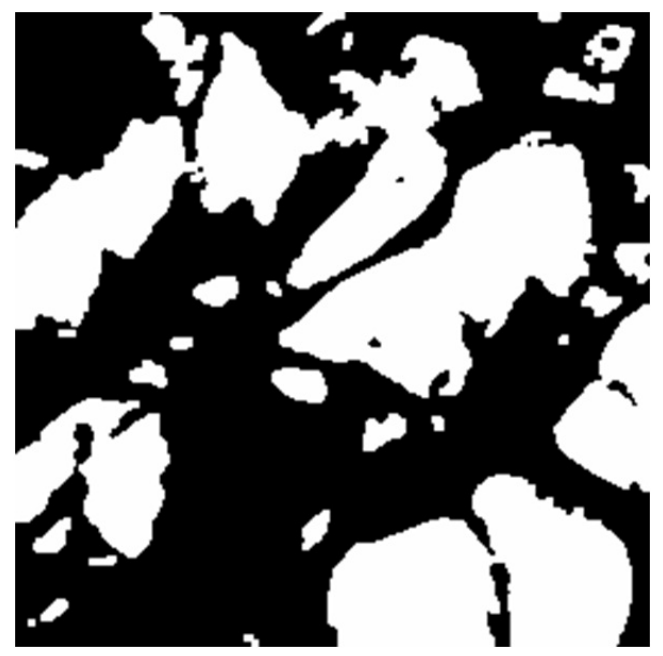

Gambar 4: Tampilan mikrografi SEM sampel hasil proses threshold gambar.

bentuk file Excel. Hasil gambar pada tahap ini ditunjukkan Gambar 5.

Dari Image-J diperoleh data luas permukaan total sampel yang dianalisis (AT) dan luas total pori yang teranalisis dari sampel (ATP). Maka porositas dapat dihitung dengan persamaan:

$$
\varphi=\frac{A_{T}}{A_{T P}} \times 100 \%
$$

Flowchart ke-3 tahapan tersebut seperti Gambar 6.

\section{HASIL DAN PEMBAHASAN}

\section{Analisis nilai densitas (Hardness)}

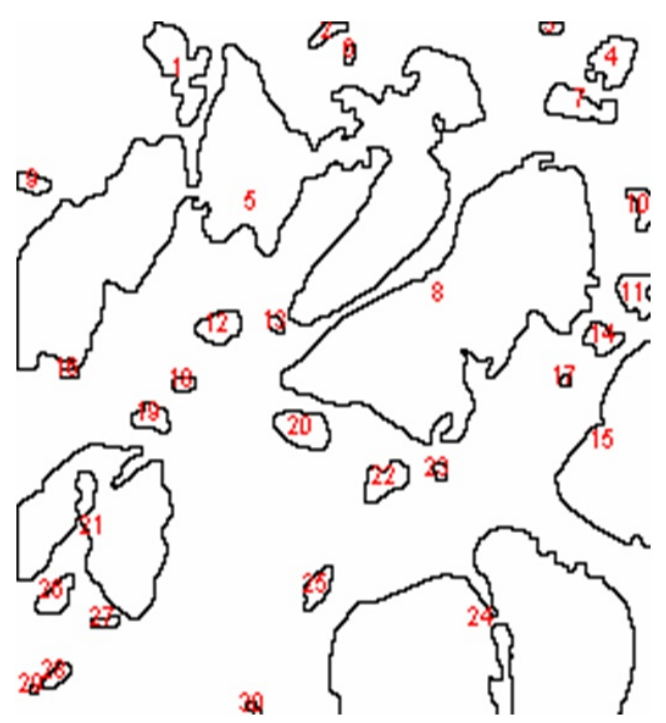

Gambar 5: Tampilan mikrografi SEM sampel hasil analyze particles dengan software Image-J.

TABEL I: Nilai densitas batu apung Lombok hasil uji dengan metode Archimedes.

\begin{tabular}{cccccc}
\hline \hline \multicolumn{6}{c}{ Loka- } \\
si & an $(\mathrm{m})$ & Asliam- & Kering & Jenuh & Jenuh $(\%)$ \\
\hline I & $\pm 0,3$ & 0,745 & 0,729 & 1,105 & 51,57 \\
& $\pm 3,0$ & 0,610 & 0,594 & 1,068 & 79,71 \\
II & $\pm 0,3$ & 0,753 & 0,737 & 1,057 & 43,47 \\
& $\pm 3,0$ & 0,736 & 0,724 & 1,148 & 58,62 \\
III & $\pm 0,3$ & 0,640 & 0,627 & 1,139 & 81,72 \\
& $\pm 3,0$ & 0,667 & 0,650 & 1,067 & 64,03 \\
\hline \hline
\end{tabular}

Nilai densitas suatu batuan berkaitan dengan seberapa rapat material penyusun membentuk batuan tersebut. Nilai densitas batu apung yang akan dianalisis adalah densitas asli (natural density), densitas kering (dry density) dan densitas jenuh (saturated density). Sampel dipanaskan dengan suhu $200^{\circ} \mathrm{C}$ selama 2 jam dan dijenuhkan dalam aquades selama 48 jam. Dengan metode Archimedes diperoleh nilai densitas seperti pada Tabel I.

Tabel I memperlihatkan bahwa pada lokasi I dan II nilai densitas asli dan densitas kering untuk sampel dari kedalaman galian $\pm 0,3 \mathrm{~m}$ bernilai lebih besar dibandingkan sampel dari kedalaman galian $\pm 3,0 \mathrm{~m}$. Pada lokasi III nilai densitas asli dan densitas kering sampel dari kedalaman galian $\pm 0,3$ $\mathrm{m}$ bernilai lebih kecil dibandingkan sampel dari kedalaman galian $\pm 3,0 \mathrm{~m}$. Keadaan ini konsisten dengan nilai massa percontoh hasil pengukuran.

Nilai densitas jenuh adalah densitas material yang terisi fluida secara maksimum. Hal ini berkaitan tingkat serapan material terhadap fluida yang dijelaskan oleh nilai kadar air jenuh material. Tabel I memperlihatkan bahwa nilai kadar air jenuh terendah dimiliki sampel dari lokasi II kedalaman galian $\pm 0,3$ $\mathrm{m}$ dan nilai kadar air tertinggi dimiliki oleh sampel dari lokasi III kedalam galian $\pm 3,0 \mathrm{~m}$. Keadaan ini dapat dicermati lebih lanjut pada Gambar 7 . 


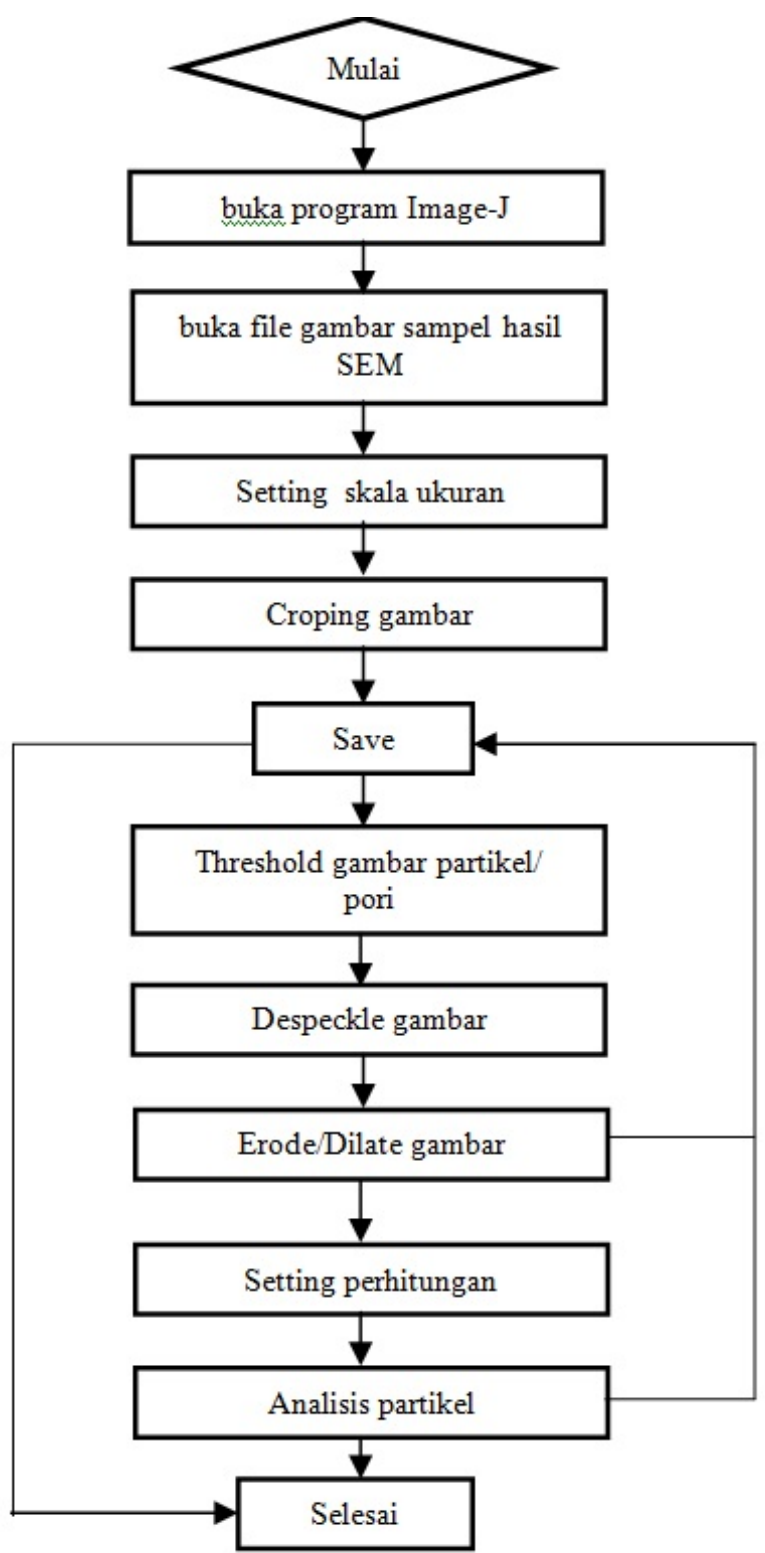

Gambar 6: Flowchart tahapan analisis mikrografi SEM sampel dengan software Image-J.

Densitas batu apung berkaitan dengan material-material penyusun dan struktur yang terbentuk. Struktur material penyusun batu apung dipengaruhi oleh proses-proses yang terjadi pada tahap pembentukan material, kandungan material hasil erupsi gunung api, kecepatan aliran lava, jarak lokasi pengambilan sampel dari sumber erupsi, ketinggian tempat endapan piroklastik berada, serta material baru yang terbawa hujan yang meresap ke dalam tanah dan mengendap dalam rentang waktu hingga ratusan tahun.

Penelitian ini mendapatkan nilai densitas asli sebesar $(0,610-0,753) \mathrm{gram} / \mathrm{cm}^{3}$, densitas kering sebesar $(0,594-$ $0,737) \mathrm{gram} / \mathrm{cm}^{3}$, dan densitas jenuh sebesar $(1,057-1,148)$ $\mathrm{gram} / \mathrm{cm}^{3}$. Nilai densitas asli tertinggi diperoleh dari sampel
TABEL II: Nilai porositas hasil metode Archimedes dan analisis software Image-J.

\begin{tabular}{|c|c|c|c|}
\hline \multirow{3}{*}{ Lokasi } & \multirow{3}{*}{$\begin{array}{c}\text { Keda- } \\
\text { laman } \\
(\mathrm{m})\end{array}$} & \multicolumn{2}{|c|}{ Porositas (\%) } \\
\hline & & Metode & Software \\
\hline & & Archimedes & Image-J \\
\hline \multirow[t]{2}{*}{1} & $\pm 0,3$ & 37,61 & 38,38 \\
\hline & $\pm 3,0$ & 47,37 & 42,64 \\
\hline \multirow[t]{2}{*}{ II } & $\pm 0,3$ & 32,03 & 38,47 \\
\hline & $\pm 3,0$ & 42,43 & 56,80 \\
\hline \multirow[t]{2}{*}{ III } & $\pm 0,3$ & 51,20 & 55,48 \\
\hline & $\pm 3,0$ & 41,65 & 54,7 \\
\hline
\end{tabular}

lokasi II kedalaman galian $\pm 0,3$ meter dari permukaan tanah.

\section{Analisis nilai porositas (Hardness)}

Porositas material padat menunjukkan rasio volume rongga-rongga pori terhadap volume total seluruh material padat tersebut. Semakin besar porositasnya, semakin tinggi serapannya terhadap fluida. Dengan metode Archimedes dan analisis mikrografi SEM sampel menggunakan software Image-J diperoleh nilai densitas seperti pada Tabel II.

Dari Tabel II terlihat bahwa pada ketiga lokasi pengambilan sampel nilai porositas batu apung hasil uji menggunakan metode Archimedes memiliki kecenderungan sama dengan nilai porositas batu apung hasil analisis mikrografi SEM sampel dengan software Image-J. Pada lokasi I dan II porositas batu apung semakin besar dengan semakin dalamnya tempat deposit. Pada lokasi III porositas batu apung semakin kecil dengan bertambahnya kedalaman tempat deposit. Keadaan ini lebih lanjut dapat dilihat pada Gambar 5. Kecenderungan nilai porositas ini konsisten dengan nilai densitasnya, dimana densitas berbanding terbalik dengan porositas.

Selain itu, Tabel II juga memperlihatkan bahwa nilai-nilai porositas yang diperoleh dengan metode Archimedes memiliki rentang nilai yang tidak jauh berbeda dengan hasil analisis software Image-J. Nilai porositas hasil metode Archimedes sebesar $(36,18-51,20) \%$. Nilai porositas hasil analisis software Image-J sebesar $(38,38-56,80) \%$. Dengan demikian software Image-J relevan digunakan untuk menentukan nilai porositas pembanding dari analisis mikrografi SEM sampel.

\section{Struktur mikro (Hardness)}

Mikrografi SEM memberikan informasi tentang orientasi kristalin, distribusi material penyusun, cacat, batas butir, ukuran butir atau pori yang menjadi dasar untuk memperkirakan sifat-sifat bahan. Tampilan mikrografi SEM batu apung Lombok seperti pada Gambar 9.

Dari Gambar 9 terlihat bahwa tekstur struktur mikro SEM batu apung Lombok terdiri dari pori-pori dengan ukuran yang berbeda. Distribusi pori mempengaruhi tebal batas antar pori dalam satu permukaan sampel. Semakin merata distribusi pori, tebal batas pori semakin lebih merata. Keadaan ini berdampak pada tingkat densitas, dan porositas sampel. Semakin tebal batas-batas pori, densitasnya semakin besar sedangkan porositasnya semakin kecil. 


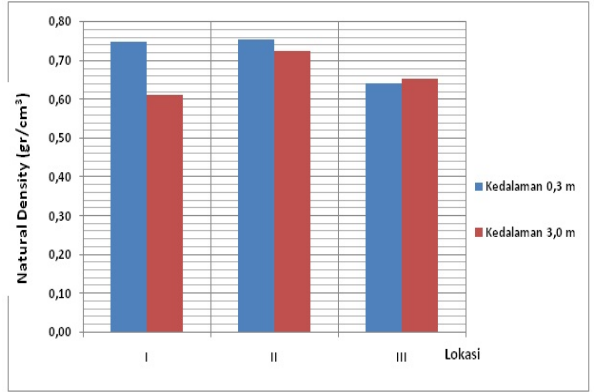

(a)

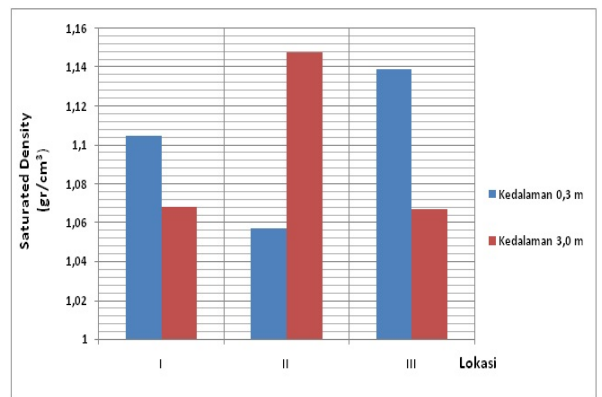

(c)

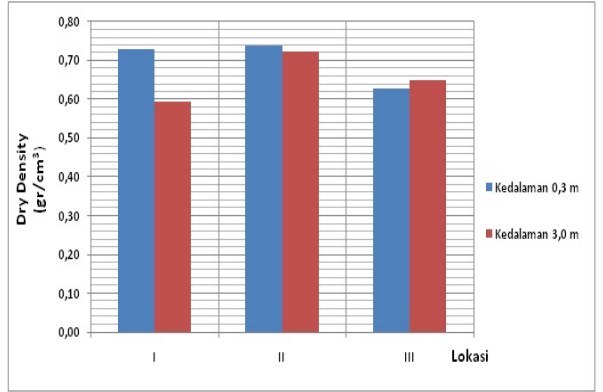

(b)

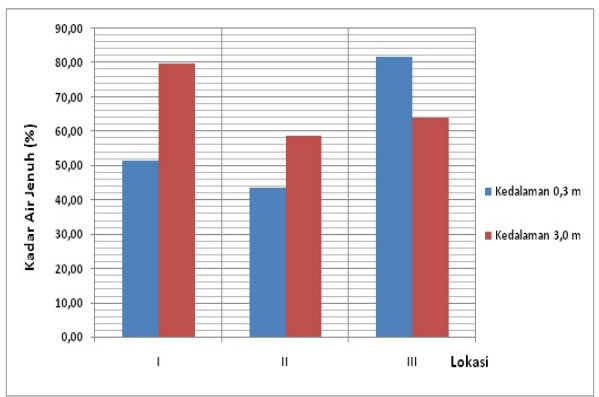

(d)

Gambar 7: Nilai densitas batu apung Lombok dari tiga lokasi pengambilan sampel.

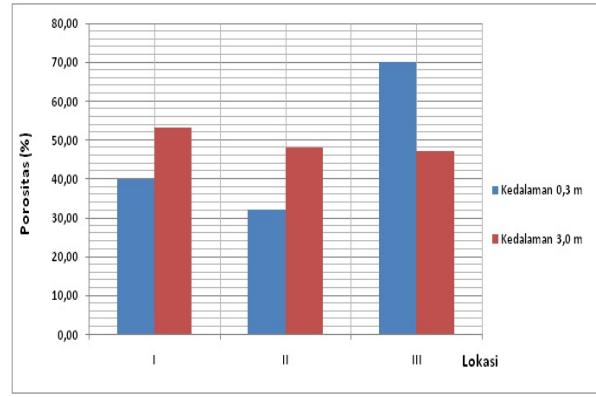

(a)

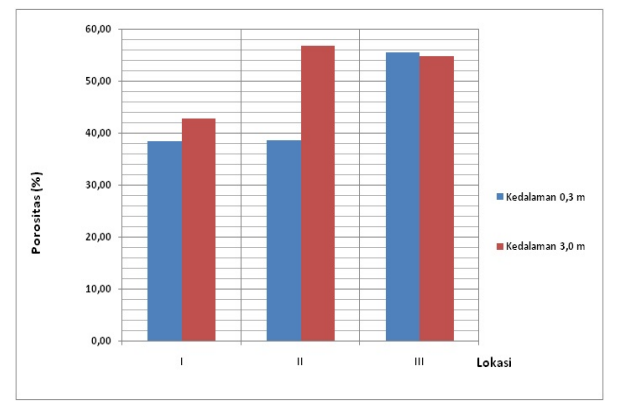

(b)

Gambar 8: Kecenderungan porositas batu apung terhadap kedalaman galian.

Gambar 9 menunjukkan bahwa pada lokasi I dan II, sampel dari kedalaman $\pm 0,3 \mathrm{~m}$ memiliki rataan ukuran pori yang lebih kecil dibandingkan sampel dari kedalaman $\pm 3,0$ m. Tebal batas antar pori sampel dari kedalaman $0,3 \mathrm{~m}$ lebih besar dibandingkan sampel dari kedalaman $\pm 3,0 \mathrm{~m}$. Dampaknya, densitas sampel dari kedalaman $\pm 0,3 \mathrm{~m}$ lebih besar dari sampel kedalaman $\pm 3,0 \mathrm{~m}$. Porositas sampel dari kedalaman 0,3 $\mathrm{m}$ lebih kecil dibandingkan sampel dari kedalaman $\pm 3,0 \mathrm{~m}$. Pada lokasi III, sampel dari kedalaman $\pm 0,3$ $\mathrm{m}$ memiliki rataan ukuran pori yang lebih besar dibandingkan sampel dari kedalaman $\pm 3,0 \mathrm{~m}$. Tebal batas antar pori sampel dari kedalaman $\pm 0,3 \mathrm{~m}$ lebih kecil dari sampel kedalaman \pm 3,0 m. Dampaknya, densitas sampel dari kedalaman $\pm 0,3 \mathrm{~m}$ lebih kecil dari sampel kedalaman $\pm 3,0 \mathrm{~m}$. Porositas sampel dari kedalaman $\pm 0,3 \mathrm{~m}$ lebih besar dibandingkan sampel dari kedalaman $\pm 3,0 \mathrm{~m}$. Hal ini konsisten dengan hasil uji densitas dan porositas dengan metode Archimedes.

\section{SIMPULAN}

Lokasi keberadaan deposit batu apung dan kedalaman galian mempengaruhi densitas dan porositasnya. Dari penelitian ini diperoleh nilai densitas asli batu apung Lombok sebesar $(0,610-0,753) \mathrm{gram} / \mathrm{cm}^{3}$, densitas kering sebesar $(0,594-$ $0,737) \mathrm{gram} / \mathrm{cm}^{3}$, dan densitas jenuh sebesar $(1,057-1,148)$ gram $/ \mathrm{cm}^{3}$. Nilai densitas asli tertinggi diperoleh dari sampel lokasi II kedalaman galian $\pm 0,3$ meter dari permukaan tanah. Nilai porositas diperoleh sebesar $(32,03-51,20) \%$. Nilai porositas tertinggi diperoleh dari sampel lokasi III kedalaman galian $\pm 0,3$ meter dari permukaan tanah. Mikrografi SEM batu apung menunjukkan bahwa struktur mikro batu apung memiliki tekstur berpori (vasikular) dengan ukuran pori yang berbeda-beda dan secara umum terdistribusi merata. Dengan analisis software Image-J, nilai porositas diperoleh 


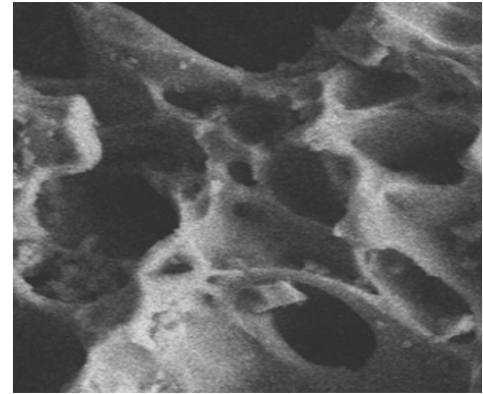

(a) $\pm 0,3(\mathrm{~m})$, Lokasi I

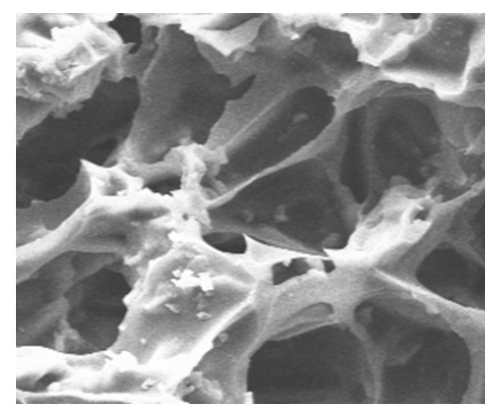

(d) $\pm 3,0(\mathrm{~m})$, Lokasi I

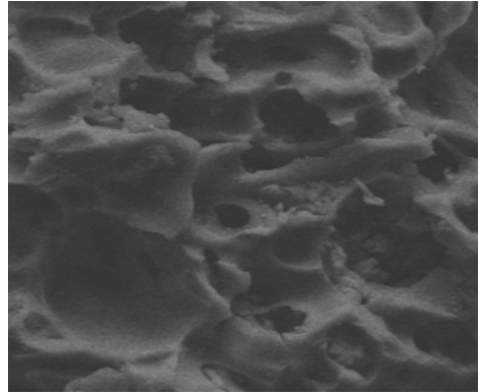

(b) $\pm 0,3(\mathrm{~m})$, Lokasi II

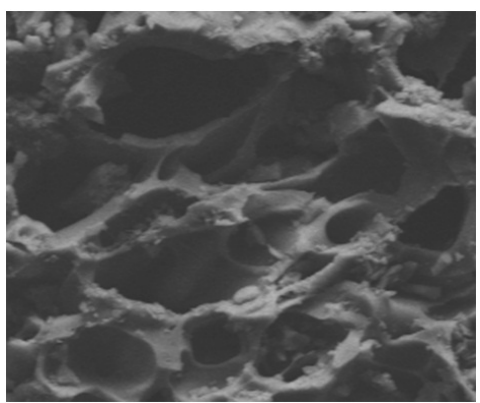

(e) $\pm 3,0(\mathrm{~m})$, Lokasi II

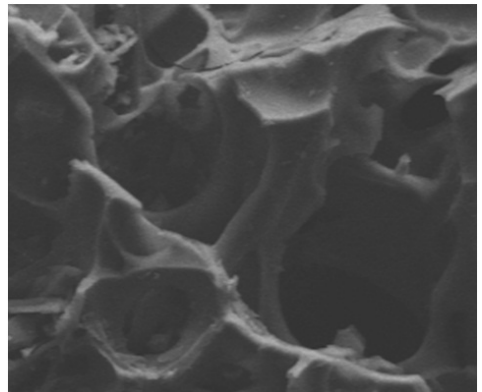

(c) $\pm 0,3(\mathrm{~m})$, Lokasi III

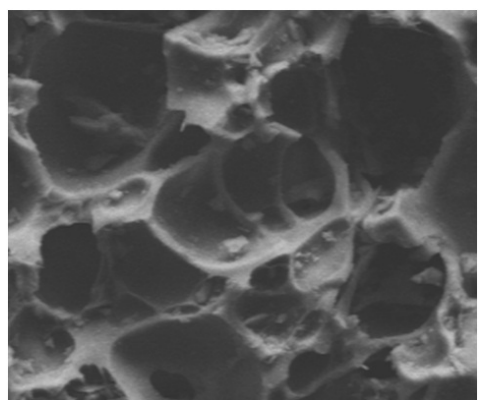

(f) $\pm 3,0(\mathrm{~m})$, Lokasi III

Gambar 9: Mikrografi SEM dengan perbesaran 1000 kali skala $50 \mu$ m material batu apung Lombok, untuk variasi kedalaman dan lokasi.

sebesar $(38,38-56,80) \%$. Dengan hasil ini, software Image$\mathrm{J}$ relevan digunakan untuk menentukan porositas dari gambar
SEM sampel batu apung.

Lightweight Building Blocks (Eastern Mediterranien University, 2010).

[7] B.M. Das, Principles of Foundation Engineering (Second Edition, PWS Kent Publishing Company, Boston, 1990).

[8] L.F. ATHY, Bull. Amer. Assoc. Petrol. Geol., 14, 1-24 (1930).

[9] http://petrowiki.org

[10] C. Kurniawan, dkk., Analisis Ukuran Partikel Menggunakan Free Software Image-J, Pusat Penelitian Fisika, LIPI, 2015. 